\title{
Determining the Epicenter of a Future Short-Focus Earthquake Tens of Hours before Earthquake and Reducing the Magnitude of an Impending Catastrophic Earthquake
}

\author{
Michael G. Noppe (i) \\ Department of Applied and Theoretical Physics, NSTU (retire), Kiryat Yam, Israel \\ Email: noppe.mg@gmail.com
}

How to cite this paper: Noppe, M.G. (2019) Determining the Epicenter of a Future ShortFocus Earthquake Tens of Hours before Earthquake and Reducing the Magnitude of an Impending Catastrophic Earthquake. International Journal of Geosciences, 10, 785-799.

https://doi.org/10.4236/ijg.2019.108044

Received: July 18, 2019

Accepted: August 27, 2019

Published: August 30, 2019

Copyright $\odot 2019$ by author(s) and Scientific Research Publishing Inc. This work is licensed under the Creative Commons Attribution International License (CC BY 4.0).

http://creativecommons.org/licenses/by/4.0/

\begin{abstract}
The article describes a project proposed to determine the epicenter of a future short-focus earthquake tens of hours before and to reduce the magnitude of an impending catastrophic earthquake. It focuses on developing a physical model to determine the conditions necessary for the start of an earthquake, for a method based on the registration of flows of mercury vapor in the gas rising from the Earth. This model gives an explanation of why an earthquake precursor appears so early (such a long period of time can range from a few to hundreds of hours). Normally, the characteristic times of an earthquake precursor for seismic methods are tens of seconds. The project is based on the physical and mathematical models of an earthquake. The derived formula for the time of the precursor of a future earthquake allows us to explain and to describe the time increase for the precursor, depending on the magnitude of the earthquake. The method of reducing the magnitude of an impending catastrophic earthquake is based on the proposed physical model of the onset of an earthquake and is implemented by the action of a vibration source in the region of the detected earthquake epicenter. The proposed system should save citizens, lives from future short-focus earthquakes.
\end{abstract}

\section{Keywords}

Earthquakes Prediction, Physical Model, Earthquake Condition, Earthquake Precursor, Precursor Time Formula

\section{Introduction}

In July 2018, 30 short-focus weak earthquakes (with the hypocenter depths of 1 - 
$15 \mathrm{~km}$ ) occurred in the region of Tiberias (Israel). According to the world classification [1], an earthquake with a magnitude of up to 5 is considered weak, a magnitude up to 7-average, and a magnitude above 7-strong or destructive. The leadership of the Homeland Service has concluded that a global cataclysm could occur in the country in the near future, which would lead to the largest civilian casualties. Currently developed systems, capable of predicting earthquakes over a fairly long period of time before an earthquake occurs, have not yet achieved significant success (see Appendix). A new multi-year plan to protect the state from earthquakes has been announced. This article describes a proposal to determine the epicenter of a future short-focus earthquake in tens of hours and reduce the power of an impending catastrophic earthquake. The presentation of the project is based on the proposed physical and physical-mathematical models of short-focus earthquakes, which allow us to understand and describe the occurrence of such large periods of time for the harbingers of a catastrophic short-focus earthquake. It is intended that the results of the work are to be protected by patent. The prototype of the patent is a patent [2] and an article [3] based on measuring the flow of mercury vapor from the Earth to the atmosphere, which is a precursor of earthquakes.

Section 2 provides information on the use of mercury measurements as earthquake precursors. Section 3 describes the physical concepts of earthquakes. The physical model of a short-focus earthquake, which formulates the conditions for the occurrence of an earthquake, is presented in Section 4. Section 5 presents the physical-mathematical model of an earthquake. Section 6 describes the proposed method for determining epicenter of earthquakes. Conclusions are presented in Section 7.

\section{Information on the Use of Mercury Flux Measurements as Earthquake Precursors}

An increase in mercury gas $\mathrm{Hg}$ was recorded in the Tashkent region after the 1966 earthquake, and it was suggested that Hg may be a precursor of an earthquake [4]. In Russia, equipment and methods for measuring mercury gas to determine information about a future earthquake have been developed since 1968 [4]. In the paper [3] and in the patent [2], the invention of the method for predicting earthquakes was described, and it forms the prototype for our further work. In the article [3], the author cites the conclusion, made by Chinese experts, that mercury anomalies are the best precursor of earthquakes. The triumph of the program in China was the prediction of the earthquake of February 4, 1975 and the rescue of more than 20,000 people. The article [3] and the patent [2] describe the invention of a method for predicting earthquakes in seismically active areas based on recording the density of mercury vapors flux from the Earth to the atmosphere, which is a geochemical precursor of earthquakes. The essence of the invention: a periodic registration of a precursor of an earthquake (the density of mercury flux in the soil gas, rising from the Earth) is carried out, and then the possibility of an earthquake can be predicted based on the ano- 
malous change in the value of the density of flux recorded over time. Empirical data accumulated during the monitoring at the observation point suggested that the content of mercury vapor in a closed cavity inside loose layers may change with an increased amplitude (10 - 1000 times) in a space of just a few hours, which correlates with subsequent earthquakes. The accumulated data shows that an earthquake is preceded by the appearance of a predecessor, evident in a short-term increase in the mercury content in the gas contained in the chamber, 4 - 40 hours before the earthquake. In addition, there are positive correlations between the amplitude of the predecessor, the power of the earthquake and the length of the period between the appearance of the precursor and the moment of the earthquake. Depending on the magnitude, such precursors can be recorded at a distance of $100 \mathrm{~km}$ or more from the sources of the earthquake. Figure 1 (Figure 1 of [2]) presents the measurement of the density of mercury flux before the September 29, 1981 earthquake in Dushanbe, with a magnitude of 3 points and an epicenter located at a distance of $20 \mathrm{~km}$ from the measurement point, which showed a 90 times increase in the flow of mercury vapor 19 hours before the earthquake.

\section{Conceptual Ideas about Earthquakes}

In this section physical representations of earthquakes are considered, following the conceptual system of hypotheses described by Gilat A. and Vol A. [5] [6] [7]. This hypothesis system can explain all the actual facts about earthquakes and volcanic eruptions, which the conceptual system of hypotheses of Reid H.F. [8] could not explain with the hypothesis of an earthquake as a result of the displacement of rocks with accumulated elastic stress. The Reid model has problems in explaining the numerous geophysical and geochemical anomalies that precede and accompany earthquakes. The following phenomena are among these anomalies: 1) powerful gas emissions before and during an earthquake; 2) abnormally high infrared radiation, in other words, heat radiation, that precedes

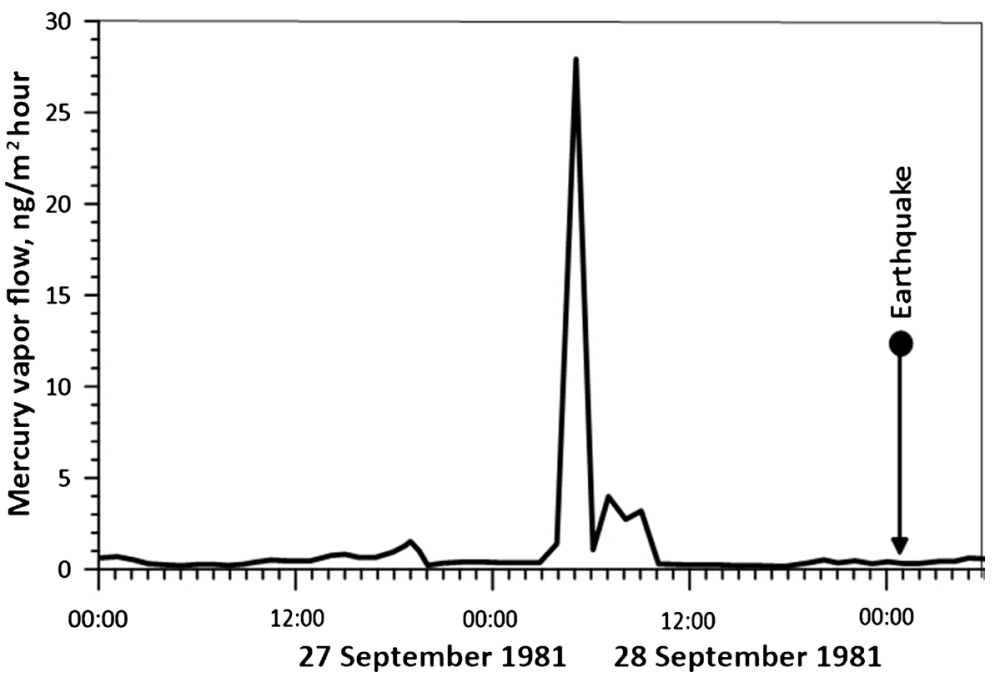

Figure 1. Measurement of mercury flux density before the September 29, 1981 earthquake in Dushanbe (from Figure 1 of [2]). 
earthquakes; 3) radio and acoustic noise before the earthquake; 4) diffused glow and ball lightning; 5) completely measureable rise of the ground, before an earthquake; 6) stress cycles associated with earthquakes and changes in groundwater regimes [5].

During the Earth's accretion period primordial hydrogen and helium, comprising 98\% - 99\% of the space matter, were trapped and stored in the Earth's core and mantle through endothermic reactions as both solid and liquid solutions and chemical compounds. After the planet stabilized, the energy gained by the capture of $\mathrm{H}$ and $\mathrm{He}$ has been quasi-continuously released by the exothermic reactions of the degassing of the Earth. The resulting heat and continuous explosions produce the manifestations of magmatic activity in general, particularly volcanic eruptions and earthquakes. Analyses of gases in lavas from Kamchatka volcanoes show that primary explosive gases uncontaminated by meteoric water and air $\left(\mathrm{H}_{2}, \mathrm{Cl}_{2}, \mathrm{CO}, \mathrm{OH}, \mathrm{F}_{2}, \mathrm{Br}_{2}, \mathrm{H}_{2} \mathrm{~S}\right.$, and $\left.\mathrm{CH}_{4}\right)$ comprise $10 \%-70 \%$ of total volcanic gases. Saturated with energy gases break through fragile rocks and form passages for magma into magmatic chambers, as well as supplying with energy the earthquakes and volcanic eruptions. Tectonic earthquakes are presented and discussed as a series of chemical explosions caused by chemical chain branching reactions [7]. This declaration is supported by comparative analysis of seismograms from earthquakes and nuclear explosions, because the complexity of earthquakes is greater than that of artificial explosions. The accumulation of energy in the hypocenter includes the latent energy of chemically active (explosive) substances which induce exothermic explosions. Those gases ascend along faults and fractures from the depth of about $700 \mathrm{~km}$ to the Earth's surface and form the complex of an earthquake. The following possible reactants participate in earthquakes: hydrogen-oxygen; hydrogen-halogens; hydrogen-sulfur; alkanes (methane, etc.)-oxygen; alkanes-halogens; alkanes-nitrates, etc. In the next section an explanation of the required conditions for the onset of an earthquake in Tiberias region is given.

\section{Necessary Conditions for the Onset of an Earthquake}

What conditions are necessary for an earthquake and what is the cause of more than 30 earthquakes in the region of Tiberias within one month of 2018? The Syrian-African Rift passes through Tiberias and opens up the possibility of the passage of explosive gases to the surface of the Earth. Statistics show that July is the month when earthquakes are most likely. Explosive gases on the way to the surface of the Earth get trapped, surrounded by poorly permeable rocks, which causes accumulation of gases in the traps. Explosiveness of combustible gases depends on their concentration and the concentration, of air, as described in [9]. The concentration of gas vapors in the air is calculated as a percentage of a given volume of air (\% volume). A mixture of gas and air is explosive only if the content of the combustible gas in it is between the lower and upper limits of explosiveness. The concentration of a combustible gas in the air, below which the 
combustible mixture cannot explode, but above which it can burn as a result of the explosion, is called the lower explosive limit (LEL). The concentration of gas or vapor, below which an explosion occurs and above which the mixture is not capable of igniting, is called the upper explosion limit (UEL). The range between the LEL and the UEL is known as the explosion range for this gas. Table 1 (from [9]) presents the explosive limits of certain gases of Kamchatka volcanoes (described in Section 3).

Thus, the necessary condition for the onset of an earthquake is that an explosive gas has to be in the explosiveness range for that gas. The natural gas consists mainly of methane $\left(\mathrm{CH}_{4}\right)$-from $70 \%$ to $98 \%$. The composition of the natural gas may include heavier hydrocarbons-methane homologues: $\mathrm{C}_{2} \mathrm{H}_{6}, \mathrm{C}_{3} \mathrm{H}_{8}$, and $\mathrm{C}_{4} \mathrm{H}_{10}$. Natural gas also contains other substances that are not hydrocarbons: $\mathrm{H}_{2}$, $\mathrm{H}_{2} \mathrm{~S}, \mathrm{~N}_{2}, \mathrm{Hg}, \mathrm{He}$, and other gases. Therefore, we assume that the main possible explosives associated with earthquakes in the Tiberias region are alkanes (methane, etc.)-oxygen. The next triggers that can cause an explosion can be: a series of branched chemical chain reactions, tidal interaction, and atmospheric pressure gradients. For deep-focus earthquakes, other compounds can play the role of an oxidizer, but in this article only small-focus earthquakes will be considered. Thus, the proposed earthquake model provides a physical explanation for the existence of earthquake precursors as follows. Let us consider the experimental measurements presented in Figure 1. The delta-shaped over time flow of $\mathrm{Hg}$ gas and an explosive gas in the area adjoining the fault fills earthquake traps with an explosive gas throughout the region, turning them into sources of future earthquakes. The density of an explosive gas after it fills the traps is significantly higher than the upper explosion limit (UEL) (see Table 1); therefore, an earthquake cannot immediately occur. The experimentally measured density of gas flow, as presented in Figure 1, is the forerunner of the earthquake. In this case, the delta-shaped gas flow should be observable throughout the region. The source of the earthquake, having been filled with gas, begins to diffuse the explosive gas in all directions. This process will continue until the gas concentration falls into the explosion range in a period of time $\mathrm{T}$, which will be the time of an earthquake precursor, after which an earthquake will occur. Thus, this process allows us to explain the physical reason for the appearance of the precursor such a long period of time ahead of an earthquake. The origin of the 2 earthquakes in Figure 3 of [2] can be explained by the fact that there were two traps in the area of the fault, which, having filled with gas, exploded on December 27 and December 28, 1993.

Table 1. Explosive limits of various gases from the Earth.

\begin{tabular}{ccc}
\hline Gas & Lower explosion limit (LEL) volume \% & Upper explosion limit of (UEL) volume \% \\
\hline $\mathrm{CO}$ & 16.4 & 75.1 \\
$\mathrm{H}_{2}$ & 9.4 & 66.5 \\
$\mathrm{CH}_{4}$ & 6.0 & 6.7 \\
$\mathrm{H}_{2} \mathrm{~S}$ & 4.3 & 25.5 \\
\hline
\end{tabular}


Similar reasons (filling of all 30 traps by gas, coming from the Syrian-African fault) can explain the origin of 30 earthquakes in July 2018 in the region of Tiberias. The existence of traps that have the ability to become earthquake foci is determined by the requirement: the diffusion coefficient $\mathrm{D}$ (center) $\ll \mathrm{D}$ (surrounding rocks). For example, for mercury D (samples of dry rocks) $0.1\left(\mathrm{~cm}^{2} / \mathrm{s}\right)$ $\gg \mathrm{D}$ (samples of natural moisture) $10^{-5}\left(\mathrm{~cm}^{2} / \mathrm{s}\right)$ [10]. The hydrothermal shell in the Tiberias region is saturated with water resources: first, it is the Kinneret; secondly, it is the Thermal springs of Khamei Tiberias located near the city of Tiberias. Therefore, the probability of the formation of earthquake foci in the region of Tiberius in the future is very high.

Earthquakes as a process are quite complicated and have different mechanisms. It can be assumed, that the following chemical reactions in the focus of a short-focus earthquake are an important mechanism influencing the onset of an earthquake.

In the conditions of lack of oxygen all hydrocarbons emit carbon dioxide and water. For example:

$$
\mathrm{CH}_{4}+3 \mathrm{O}_{2}=\mathrm{CO}_{2}+2 \mathrm{H}_{2} \mathrm{O} \text {. }
$$

With an even smaller amount of oxygen, fine carbon (soot) is released:

$$
\mathrm{CH}_{4}+\mathrm{O}_{2}=\mathrm{C}+2 \mathrm{H}_{2} \mathrm{O} \text {. }
$$

For an earthquake to occur, oxygen is also needed in its focus. Therefore, the more time passes from the moment of filling the trap with gas, the less oxygen is present in the focus due to reactions (1), (2), which ultimately leads to an increase in the precursor time and, therefore, to a decrease in the power of the earthquake. It can be assumed that another important mechanism affecting the onset of an earthquake is a decrease in atmospheric pressure on the Earth's surface (i.e., a cyclone burst). One of the signs of a cyclone is the prevailing area of calm weather in the center of the cyclone. Inside this area, a warmer temperature is formed than in the rest of the air flow and lower humidity is observed [11].

The analysis of the observational data for the largest earthquakes with $M \geq 7.5$ for the period 2000-2010 [12] indicates a correlation of preceding negative atmospheric pressure gradients with the largest earthquakes of the $21^{\text {st }}$ century. The atmospheric pressure gradients for 42 earthquakes are shown in Table 2 and in Figure 2.

The following explanation can be given for the trigger of atmospheric pressure gradients at the beginning of an earthquake, which follows from the presented

Table 2. Atmospheric pressure gradient distribution for earthquakes with $M \geq 7.5$.

\begin{tabular}{cc}
\hline Gradient amplitude (mm Hg. St) & N earthquakes \\
\hline $4-10$ & 24 \\
$10-20$ & 9 \\
$>20$ & 9 \\
\hline
\end{tabular}




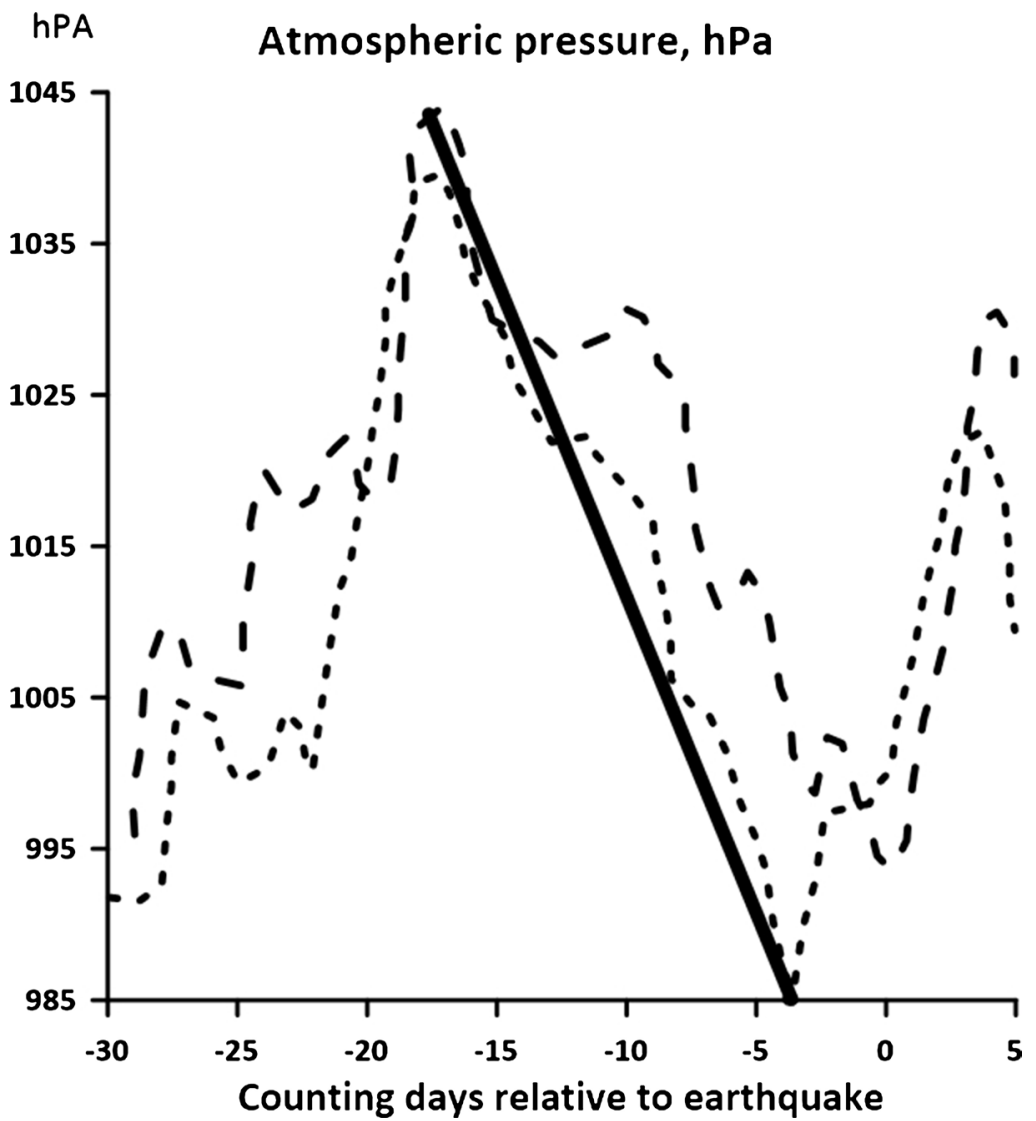

Figure 2. An example of atmospheric gradients pressure before an earthquake (depending on the number of days relative to an earthquake) with $M \geq 7.5$, registered on the 2 closest to the epicenter of observation points. 11/16/2003. $M=7.8$ Rat Islands (Aleutian Islands), Alaska. Figure 2 is given in [12]. Figure 2 shows the graphs for atmospheric pressure 30 days before and 5 days after the earthquake that occurred during a cyclone.

physical model of the onset of an earthquake. The formation of a cyclone (leading to a decrease in pressure) initiates the release of an explosive gas into the atmosphere; which in turn accelerates the decrease in the concentration of gas into the atmosphere; which in turn accelerates the decrease in the concentration of gas in the focus. This process will continue until the gas concentration falls within the explosion range, after which an earthquake will occur. Thus, the origin of thirty earthquakes in July 2018 may be associated precisely with the preceding negative gradients of atmospheric pressure in the Tiberias region. Note, that the overwhelming number of earthquakes in Israel occurred precisely in the summer months, when quiet weather with warm temperatures is usually observed [1]: July 11, 1927, August 3, 1993, June 2004, June 12, 2008, July 13, 2008, July 15, 2008, April 17, 2009, April 12, 2010, March 9, 2010, March 20, 2010, July 15, 2010, August 23, 2010.

\section{Physical and Mathematical Models of a Short-Focus Earthquake}

In this section, we consider the simplest physical and mathematical models of a 
short-focus earthquake associated with the diffusion of an explosive gas in all directions from the earthquake source, which will allow us to obtain a formula for estimating the time interval of an earthquake precursor.

The piezoelectric conductivity equation in the theory of filtration (describing the motion of a gas in a porous medium) is written as follows [13]

$$
P_{t}=æ \Delta P .
$$

where piezoconductivity coefficient $æ=(0.1 \sim 5) \mathrm{m}^{2} / \mathrm{s}$; this range for $æ$ was fixed for various environments. The accumulation of gas mass in the trap can be interpreted as the appearance of an instantaneous point source of mass $m_{0}$, which begins to diffuse the gas in space. Then, the gas $P(r, t)$ can be described by the formula (if the origin is placed in the earthquake source) [14].

$$
P(r, t)=E_{0} \exp \left(-r^{2} / 4 æ t\right) /\left(8(\pi æ t)^{3 / 2}\right),
$$

where $E_{0}=m_{0} k_{B} T_{k} / \mu, m_{0}$ is the mass of gas in the focus, $\mu\left(\mathrm{CH}_{4}\right)=2.663442 \times 10^{-26} \mathrm{~kg}, k_{B}$ is Boltzmann constant, $T_{k}$ is temperature.

The gas density $u(r, t)$ can be described by the formula (if the origin is placed in the earthquake source) in the following form:

$$
\begin{gathered}
U(r, t)=m_{0} \exp \left(-r^{2} / 4 æ t\right) /\left(8(\pi æ t)^{3 / 2}\right), \\
U(0, T)=U_{1}=m_{0} /\left(8(\pi æ T)^{3 / 2}\right) .
\end{gathered}
$$

where $U_{1}$ is the gas density at which an earthquake occurs, for example, (for $\mathrm{CH}_{4}$ and air) $U_{1}=0.08\left(\mathrm{~kg} / \mathrm{m}^{3}\right)$. The earthquake energy $E$ is equal to:

$$
E=\kappa_{1} m_{0} .
$$

The formula linking magnitude $M$ and energy of earthquakes was presented in [15] in such form:

$$
\lg (E / J)=6.5+1.449 M,
$$

where $E$ is the earthquake energy, $J$ is one joule. Then the formula for the time precursor of the earthquake $T$, using (4)-(8), can be written as following:

$$
T=10^{4.333+0.966 M}\left(J / k_{1} U_{1}\right)^{2 / 3} / 4 \pi æ .
$$

We calculate $T=19$ hours, using (9) and $M=3, k_{1}=2.76 \mathrm{MJ} / \mathrm{kg}$, $U_{1}=0.08 \mathrm{~kg} / \mathrm{m}^{3}, æ=0.1169 \mathrm{~m}^{2} / \mathrm{s}$.

$$
\lg (T)=a+b M,
$$

where $a$ and $b$ are free parameters. Thus, the derived formula (9) coincides in functional structure with the empirical formula (10). Moreover, formula (9) represents expressions for the free parameters $a$ and $b$. Deviations from formulas (5) and (9) are observed in the processing of experimental measurements: earthquakes represented in a circle in Figure 3(a) in [3] with $M<5.8$ represent a cloud of points that cannot be described by a straight line. We can offer the following explanation for these deviations from formulas (5) and (9) for earth- 
quakes represented in a circle:

- the indicated earthquakes had a relatively small, different concentration of the oxidizer in the foci compared with the concentration of the oxidizer in the foci for earthquakes satisfying formulas (5) and (9);

- this scatter of small initial conditions of oxidizer concentration led to a significant increase in the time of the precursor $T$ when the gas diffusion occurred due to the absence of the necessary explosion conditions and to the scatter of points;

- in turn, due to reactions (1) and (2) this led to an even greater increase in the time of the precursor $T$ and, accordingly, to a significant decrease in the concentration of an explosive gas, when the necessary explosion condition became satisfied after the diffusion of the gas;

- as a result, the magnitude of earthquakes $M$ decreased significantly and the points describing earthquakes, due to the initial spread of oxidizer concentrations in the source, fell into the area of the circle.

\section{A Proposal of a System of Measures to Prepare for Future Earthquakes in the Tiberias Region}

In the paper [3] and in the patent [2] the invention of the method for predicting earthquakes was described, which is the prototype of our further work. The summary of the prototype analysis: the examples of determining the hypocenter and epicenter were based on the empirical formula (2) in [3], which uniquely describes only earthquakes with $M>5.5$, the physical justification of the formula (2) in [3] is not presented.

The specific form of detection of mercury in rocks discovered in the course of research [16] under normal conditions corresponds to a state close to gaseous, in which atoms "impregnate" minerals throughout their entire volume and in the interstitial space of the lattices.

It is established that the reaction of rocks to deformations, accompanied by the release of $\mathrm{Nd}$ vapors from them, serves as an effective tool for studying the dynamic processes occurring in rocks, which is used in sensors.

Our proposals:

1) A patent is proposed for a new device for recording information about earthquake precursors using mercury measurements as an extremely strong and sensitive forerunner occurring tens of hours before an earthquake. The proposed equipment for recording information should be able to determine the epicenter of a future earthquake.

2) It is proposed to create a network of stations in the north of Israel. At each station it is proposed to place a device for determining the epicenter of a future earthquake, as well as a device for determining the dependence of air pressure on time.

The prototype [2] gives a description of an invented method for predicting earthquakes in seismically active regions based on space-time variations in the density of mercury vapour flux from the Earth to the atmosphere, which is a 
geochemical precursor of earthquakes. The essence of the invention is to carry out periodic registration of the precursor of an earthquake in the set area of control. In order to do this, the magnitude of the density of mercury in the gas flux ascending from the Earth is registered at a depth of not less than $1 \mathrm{~m}$. Then, according to an anomalous change of the density value over time, the possibility of an earthquake can be forecast. In the described patent, the mercury flux can come from any direction into one sensor; the information about the direction angle of where the flow came from is lost. For example, in Figure 1, after the trap is filled, the gas diffuses from the traps, but the information about the direction from which the gas flow came to the measuring device is not recorded. It is proposed in the prototype, that the directions were the flow from the trap came from to the measuring device can be found using the formula (2) from [3], which does not describe the situation with high accuracy.

In our proposed patent, the flow of mercury from any direction of a certain solid angle $\Omega_{0}$, comes into only one sensor. The number of sensors located in the hemisphere is $N=2 \pi / \Omega_{0}$. Thus, once the delta-shaped gas flow from the fault fills all the traps in the region, the gas begins to diffuse in all directions from all the traps in the region. Now, looking at the gas flows in the entire set of sensors in the hemisphere, we can immediately determine the sensor with the maximum gas flow from all traps in the region and find the solid angle from which the maximum gas flow came to every station from all earthquakes. Considering together the maximum gas flows from several stations located in the region, we can determine the epicentres and hypocentres of future earthquakes.

\section{Prevention of Catastrophic Earthquakes by Means of Significantly Decreasing the Magnitude of a Future Earthquake}

The method of finding the epicenter of a future earthquake is described in the Section 6. This section describes the proposed reduction in the magnitude of a future earthquake by slowing down the process of an explosive gas release from the earthquake source, which should prevent catastrophic earthquakes basing on the paper [17]. Studies of excited seismicity in the reservoir area. The dams of the Nurek hydroelectric station showed that with an increase in the level of vibrations during spillways, the average daily seismic energy normalized to an area of $1000 \mathrm{~km}^{2}$ decreases by 3 orders of magnitude and strong earthquakes disappear. Figure 3 shows that with an increase in the level of vibrations from 0.02 $\mu \mathrm{m}$ (the natural level of microseisms) to values of $0.4 \mu \mathrm{m}$, the average daily released seismic energy, normalized to an area of $1000 \mathrm{~km}^{2}$, decreases by 3 orders of magnitude. In separate periods of time, when the amplitudes of technogenic vibrations in the adjacent territories reached a maximum value of $0.5 \mu \mathrm{m}$ during spillway, earthquakes completely disappeared.

The authors suggest the following set of activities:

1) Creation of a network of seismic observations in a seismically active fault 


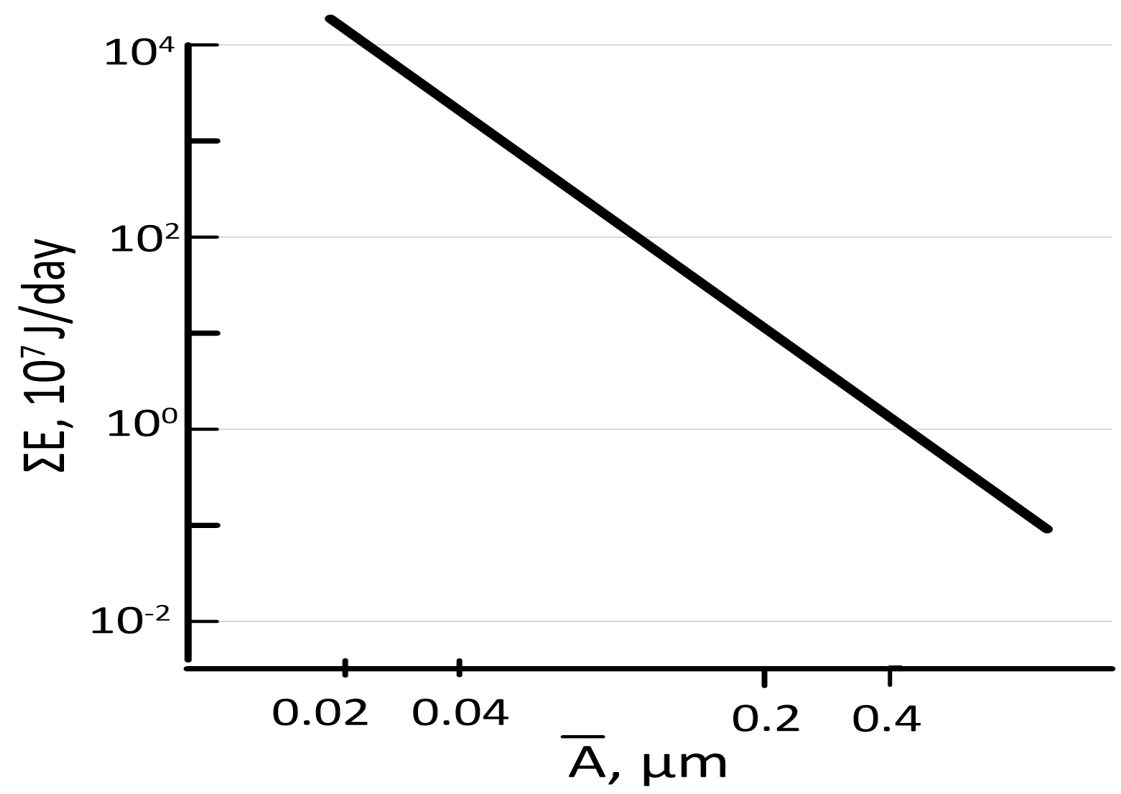

Figure 3. Schedule of the average daily released earthquake energy per unit area of 1000 $\mathrm{km}^{2}$ in the water area of the Nurek hydroelectric dam, depending on the level of microseisms at different distances and at different time periods for gradually receding zones within a radius of $25 \mathrm{~km}$ from the spillway from [17].

zone with an energy level of representative recording of $K \geq 7(M=1.5)$. 2) Determination of the most probable places of expected strong earthquakes within a large seismic generating structure. 3) Creation of a complex of measurements of horizontal and vertical movements. Earth surface using GPS/GLONAS systems, including deformation measurements in adits. 4) Creation of a complex for regulating water injection into wells and vibration effects in areas of the likely occurrence of strong earthquakes. 5) Periodic injection of fluid into the wells in the phases of gravity lunar-solar tides of the earth's crust, causing the expansion of tension environments. 6) Conducting vibrations of the earth's crust in areas of likely occurrence of earthquakes with an intensity of up to 0.5 microns.

Based on the derivation of the formula for the time precursor of the earthquake $T$ in Section 5, we write the time precursor of the earthquake $T_{1}$ when the vibro-seismic device creates an oscillation with amplitude $a$ and frequency $\omega$

$$
T_{1} / T=1 /\left(1-a c_{0}\right)^{2 / 3},
$$

where

$$
c_{0}=\dot{\omega} \rho \mu_{0} c /\left(\sqrt{2} k_{B} T_{k} U_{1}\right),\left(c_{0}=0.625 \mu \mathrm{m}^{-1}\right) .
$$

Figure 4 is constructed using formulas (9)-(10). Vibration exposure slows the release of gases and oxygen. As a result of a decrease in the emission of gases and oxygen, chemical reactions (1) and (2) will play a greater role, which should lead to an even greater violation of the necessary earthquake conditions and, consequently, to an even greater decrease in the magnitude of the earthquake. Thus, we propose to fix the epicenter of the earthquake with the help of a new sensor. Then we turn on vibrator in the epicenter of an earthquake. 


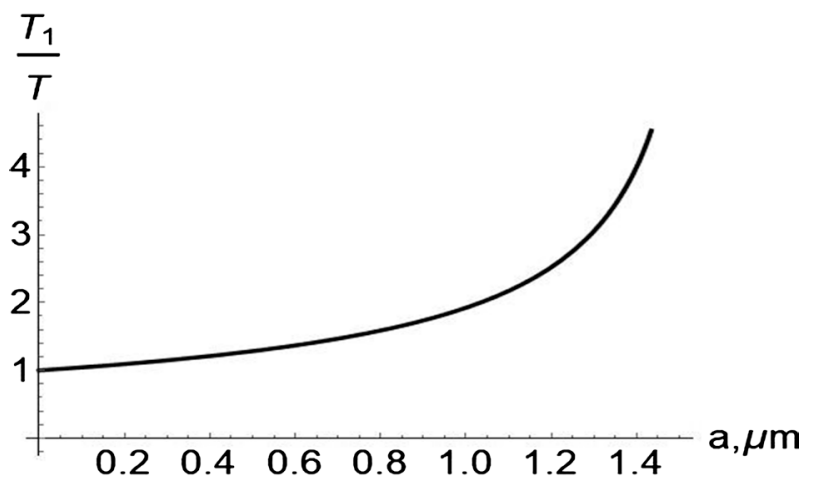

Figure 4. The ratio of the time precursor of the earthquake T1 when the vibro-seismicdevice creates a wobble to time $\mathrm{T}$ precursor of the earthquake.

\section{Conclusion}

The article presents a physical model of the conditions necessary for an earthquake to start, described for a method based on the registration of flows of mercury vapors in a gas rising from the Earth. This model gives an explanation of why a precursor appears such a long period of time ahead of an earthquake (from several hours to hundreds of hours), using a physical-mathematical model. The characteristic times of an earthquake precursor for seismic methods are tens of seconds. The formula for the time of the precursor of the future earthquake, derived from the proposed physical and mathematical model of the earthquake, made it possible to explain and describe the increase in the time when the precursor appears, depending on the magnitude of the earthquake. The developed physical model of a short-focus earthquake is the basis for the proposed project to determine the epicenter of a future short-focus earthquake tens of hours ahead of its start, and to reduce the power of an impending catastrophic earthquake. The proposed system of measures should save the lives of citizens from future catastrophic short-focus earthquakes. This article is a breakthrough in the following directions: a physical model of the onset of an earthquake has been proposed; it was formulated a necessary condition for the onset of an earthquake, which allowed explaining and theoretically describing the anomalously large time of the appearance of an earthquake precursor; Based on the proposed chemical formulas, an explanation of the deviations of the experimental observations from the formulas in the prototype was given; The article contains a patent proposal for a sensor and methods for reducing the magnitude of future catastrophic short-focus earthquakes. The results of the work are supposed to be protected by a patent. To implement the author's proposals, it is necessary to carry out the following program: development and testing of the proposed sensor, which allows determining the epicenters of future earthquakes. It is proposed to create a network of stations in the north of Israel. At each station it is proposed to place a device for determining the epicenter of a future earthquake, as well as a device for determining the dependence of air pressure on time. The method of reducing the magnitude of an impending cata- 
strophic earthquake is based on the proposed physical model of the onset of an earthquake and is implemented by the action of a vibration source in the region of the detected earthquake epicenter. Theoretical modeling of chemical processes should be the next stage of theoretical studies.

\section{Acknowledgements}

The author is grateful to Lev Gilat for sending of some materials and for helpful discussions. The author also thanks Valery Cherkasky for their assistance with making of figures.

\section{Conflicts of Interest}

The author declares no conflicts of interest regarding the publication of this paper.

\section{References}

[1] Griber, A. (2010) Earthquakes in the History of Israel. http://alfred-griber.com/proizvedeniya/ocherki-ob-izraile/zemletryaseniya-v-istoriiizrailya

[2] Staheev, Yu.I., et al. (2000) Patent 2145098 (01.27.2000)-Method of Invention for Earthquake Prediction. http://www.freepatent.ru/patents/2145098

[3] Staheev, Yu.I. (2005) Hydrogeochemical Precursors of Earthquakes. Russian Chemical Journal, 49, 110-119. http://www.chem.msu.su/rus/jvho/2005-4/110.pdf

[4] Fursov, V.Z., Wolfson, N.B. and Khvadovsky, A.G. (1968) The Results of the Study of Mercury Vapor in the Zone of the Tashkent Earthquake. Reports of the Academy of Sciences of the USSR, 179, 1213-1216.

[5] Gilat, A. and Vol, A. (2005) Primordial Hydrogen-Helium Degassing, an Overlooked Major Energy Source for Internal Terrestrial Processes. HAIT Journal of Science and Engineering B, 2, 125-167.

http://people.clarkson.edu/ nanosci/jse/B/vol0201B/vg040720.pdf

[6] Gilat, A. and Vol, A. (2012) Degassing of Primordial Hydrogen and Helium as the Major Energy Source for Internal Terrestrial Processes. Geoscience Frontiers, 3, 911-921. https://www.sciencedirect.com/science/article/pii/S1674987112000412 https://doi.org/10.1016/j.gsf.2012.03.009

[7] Mavrodiev, S.C., Pekevski, L., Botev, E., Pinar, A., Kikuashvili, G., Vol, A. and Gilat, A. (2018) Study of the Possibility of Predicting Earthquakes. International Journal of Geosciences, 9, 688. https://doi.org/10.4236/ijg.2018.912042 https://www.scirp.org/journal/PaperInformation.aspx?PaperID $=89580$

[8] Reid, H.P. (1910) The California Earthquake of April 18, 1906; the Mechanics of the Earthquake. Carnegie Institute, Washington DC. https://doi.org/10.1086/621732

[9] Frolov, K.V., et al. (2004) Mechanical Engineering. Encyclopedia. Vol. XXL, Mashinostroenie, Moscow, 912 p. http://mash-xxl.info/info/397136

[10] Alekhin, Yu.V., Kovalskaya, N.V., Lapitsky, S.A. and Minubaeva, Z.I. (2003) New Results of the Study of Diffusion and Filtration Migration of Mobile Forms of Mercury. Conference Lomonosov Readings. Section Geology, April. http://geo.web.ru/db/msg.html?mid=1169917

[11] Site Biosfera. Space. https://biosfera.space/np/ciklony-i-anticiklony-2.html 
[12] Gokhberg, M.B. and Kolosnitsyn, N.I. (2010) Trigger Mechanisms of Earthquakes. In: Adushkina, V.V. and Kocharyan, G.G., Eds., The Collection Rigger Effects in Geosystems, Academician of the Russian Academy of Sciences, Moscow, 52. http://idg.chph.ras.ru/data_files/\%D0\%A2\%D1\%80\%D0\%B8\%D0\%B3\%D0\%B3\%D 0\%B5\%D1\%80\%D0\%BD\%D1\%8B\%D0\%B5\%20\%D1\%8D\%D1\%84\%D1\%84\%D0\% B5\%D0\%BA\%D1\%82\%D1\%8B_2010.pdf

[13] Kushtanova, G.G. and Ovchinnikov, M.N. (2010) Underground Hydromechanics, Kazan University Press, Kazan, 67 p. https://www.twirpx.com/file/1463802/

[14] Tikhonov, A.N. and Samarsky, A.A. (1972) The Equations of Mathematical Physics. Science, Moscow, $736 \mathrm{p}$.

[15] Kuznetsov, V.V. (2012) 20 Lectures on Earth Physics. Lecture 8. Gorno-Altai University Press, Gorno-Altai. https://vvkuz.ru/books/lectures_2/8.pdf

[16] Stepanov, I.I. (1996) Mercury-The Indicator of "Hot" Hydrothermal Zones and Dynamic Processes Accompanied by Deformations of Mountain Species. Abstract of Thesis, Moscow.

http://earthpapers.net/rtut-indikator-goryachih-gidrotermalnyh-zon-i-dinamichesk ih-protsessov-soprovozhdayuschihsya-deformatsiyami-gornyh-porod\#ixzz5hWISy NRB

[17] Mirzoev, K.M., Nikolaev, A.V., Lucc, A.A. and Jung, S.L. (2010) Method for Removing Elastic Energy to Prevent Earthquakes. In: Adushkina, V.V. and Kocharyan, G.G., Eds., Trigger Effects in Geosystems, Academician of the Russian Academy of Sciences, Moscow, $87 \mathrm{p}$.

http://idg.chph.ras.ru/data_files/Триггерные\%20эффекты_2010.pdf

[18] Site Detaly. https://detaly.co.il/zemletryaseniya

[19] Site Detaly.

https://detaly.co.il/v-izraile-vvodyat-sistemu-preduprezhdeniya-zemletryasenij 


\section{Appendix 1}

The Canadian company "Nanometrix" offered an earthquake early warning system; this technology will allow being informed about an earthquake with an interval of 10 - 30 seconds between the first strong earthquake and the destructive wave following it [18]. In addition, the Geological Survey of Israel (GSI) is developing a system called "Troy" ("Trumpet Sound"). According to information received from the head of this seismological project, when the alarm signals are heard, tremors will already be felt in Tiberias if the epicenter is in the Kinneret area [19]. Thus, attempts to find and implement a system capable of predicting earthquakes over a sufficiently long period of time before an earthquake have not yet achieved significant success.

\section{Appendix 2}

The delta-shaped appearance of increased pressure in the earthquake source leads to the appearance of a filtering pressure wave propagating in all directions, and, accordingly, to a measurement point on the Earth's surface (pressure filtration waves have long been known and, in particular, are used to study layer parameters [Ovchinnikov, GG Kushtanova, AG Gavrilov, MV Filtrational Pressure Waves as a Method of Reservoir Flow Parameters Investigation, Oil and Gas business (electronic journal http://ogbus.ru/files/ogbus/issues/6_2015/ogbus_6_2015_p124-161_Ovchinniko vMN_en_en.pdf)].

For calculations, we use the theory of propagation of intense acoustic waves in a medium without dispersion [Vinogradova MB, Rudenko OV, Sukhorukov AP Wave Theory: Nauka, M., 1979, 383 pp.

https://nashol.com/2015033183698/teoriya-voln-vinogradova-m-b-rudenko-o-v -suhorukov-a-p-1979.html]. The problem of changing the amplitude and duration of a single triangular disturbance (see $\$ 3$, chapter 6 , c) described by the following expression for the initial form of the disturbance

$$
u / u_{0}=\left\{0, \tau<0 ;\left(1-\tau / T_{1}\right), 0 \leq \tau \leq T_{1} ; 0, \tau>0\right\},
$$

where $u$ is the vibrational velocity, $T$ is the pulse duration. Formulas describing the change in the peak value of the vibrational velocity $u_{2}(x)$ and the pulse duration $T(x)$ have the form

$$
u_{2}(x)=u_{0}(1+a x)^{-1 / 2} ; T(x)=T_{1}(1+a x)^{1 / 2},
$$

where $x$ is the distance, $a=\varepsilon u_{0} / c^{2} T_{1}, \varepsilon=(\gamma+1) / 2, \gamma$ is the adiabatic index of the medium, with the speed of the acoustic wave. Based on formulas (2.1), we write the formulas for the flux density of mercury vapor $F_{s}(t)$ in the sensor [2].

$$
\begin{gathered}
F_{0}(t)=F\left(1+\tau / T_{1}\right)^{2},-T_{1} \leq \tau \leq 0 \\
F_{1}(t)=F\left(1-t / T_{1}\right)^{2}, 0 \leq t \leq T_{1} \\
F_{2}(t)=F\left[1-\left(t-t_{3}\right) / T_{2}(y)\right]^{2} /(1+y), y=a x, t_{3}=x / c, 0 \leq t \leq T_{1} \\
F_{s}(t)=F_{0}(\tau)+F_{1}(t)+F_{2}(t), \quad-T_{1} \leq \tau \leq 0 ; 0 \leq t \leq T_{1}
\end{gathered}
$$

